\title{
Land-atmosphere interactions during a Northwestern Argentina Low event
}

\section{Celeste Saulo $^{1,2}$, Lorena Ferreira ${ }^{1,3}$, Julia Nogués-Paegle ${ }^{4}$, Marcelo Seluchi $^{5}$ and Juan Ruiz ${ }^{1,2}$}

${ }^{1}$ Departamento de Ciencias de la Atmósfera y los Océanos, Universidad de Buenos Aires, Argentina.

${ }^{2}$ Centro de Investigaciones del Mar y la Atmósfera (CONICET-UBA), Buenos Aires, Argentina.

${ }^{3}$ Servicio Meteorológico Nacional, Buenos Aires, Argentina.

${ }^{4}$ Department of Meteorology, University of Utah, USA

${ }^{5}$ Centro de Previsao de Tempo e Estudos Climaticos (CPTEC) - INPE- Brazil

To be submitted to Monthly Weather Review

September 2009

Corresponding author:

Celeste Saulo,saulo@cima.fcen.uba.ar 
Abstract

The impact of changes in soil moisture in subtropical Argentina in rainfall distribution and low level circulation is studied with a state-of-the art regional model in a downscaling mode, with different scenarios of soil moisture for a 10 day period. The selected case (starting January 29, 2003) was characterized by a Northwestern Argentina Low event associated with well defined low level northerly flow that extended east of the Andes over subtropical latitudes. Four tests were conducted at 50 $\mathrm{km}$ horizontal resolution with 31 sigma levels, decreasing and increasing the soil moisture initial condition by $50 \%$ over the entire domain, $50 \%$ reduction over northwest Argentina and 50\% increase over South East South America. A control run with NCEP/GDAS initial conditions was used to assess the impact of the different soil moisture configurations.

It was found that land-surface interactions are stronger when soil moisture is decreased, with a coherent reduction of precipitation over southern south America. Enhanced northerly winds result form an increase in the zonal gradient of pressure at low levels. In contrast, when soil moisture is increased, no circulation changes are found, though there appears to be a local feedback effect between the land and precipitation The combined effects of changes in the circulation and in local stratification induced by soil wetness modifications, through variations in evaporation and CAPE, are in agreement with what has been found by other studies, resulting in coherent modifications of precipitation when variations of CAPE and moisture flux convergence mutually reinforce. 


\section{Introduction}

The crucial role of land-atmosphere feedbacks on climate has been longrecognized in the climate modeling community. Nevertheless, large uncertainties in the representation of surface processes continue to lead to poor understanding of landatmosphere interactions. More recent, evidently significant improvements of land surface processes have arisen. These improvements are related to development of more sophisticated land surface models that, combined with available observations of soil characteristics, provide an increasingly reliable global picture of soil variables, including one generated by the Global Land Data Assimilation System (Rodell et al. 2004).

Among soil variables, much interest focuses on soil moisture, given its influence on precipitation and its variability, particularly the positive feedback through which anomalous precipitation conditions are self-sustained and amplified by the land surface state. Dirmeyer et al. (2009), using land memory estimations, provide a framework to recognize the areas where this kind of feedback is more evident. They show that, during summer, a significant portion of South America is characterized by soil moisture memory below 15 days. According to this result, precise initialization of land surface conditions, would have a positive impact in short to medium range predictability, but may not be significant at seasonal time scales.

There can be found very few studies addressing the issue of land-atmosphere coupling over South America, and most of these analyze impact of surface conditions on precipitation at monthly or seasonal time scales (Collini et al. 2008; Grimm et al. 
2007; Xue et al. 2006; among others). These studies suggest that soil moisture has an important role on precipitation variability and in the monsoon development. However, if soil memory is indeed bounded by a 15 day period -as shown by Dirmeyer et al. (2009)-, monthly means may provide weak representations of land-atmosphere coupling over large areas in South America and actual feedbacks may be hidden. Consequently, inferences obtained from climate studies could be complemented by individual case examinations. This hypothesis constitutes our rationale to select a particular case study in order to analyze in more detail the pathways for landatmosphere coupling over our region of concern, which covers southern and southeastern South America. In this context, it is of interest to understand which mechanisms account for precipitation variability occurring as a consequence of changes in soil conditions: are they mostly related with local moisture recycling and/or with changes in circulation?. Answering these questions will provide useful hints to focus on the specific improvements needed to achieve the theoretical limit of predictability, at least to the extent it can be realized by current state of the art models. Moreover, the approach permits relatively detailed analyses of thermal and dynamical responses for time scales in which forecast models retain deterministic predictability skill and also incorporates the most up-to-date modeling technology and special field observations. Similar methodology has been followed by Trier et al. 2008, Gallus and Seagal 1999 and Zhong et al. 1996 among many others, when analyzing physical processes involved in land-atmosphere interactions under specific weather systems (i.e. organized convection, cold fronts, low level jets).

Selection of a particular event is not a trivial problem, since, ideally, the prevailing synoptic circulation should remain quasi-stationary and should allow for 
the manifestation of coherent land-atmosphere interactions. On the other hand, under this kind of approach, model performance is not a minor issue, since day-by-day evolution of the system has to be correctly simulated. With these requirements in mind, we selected a Northwestern Argentina Low (NAL) event, characterized by an enhanced low level jet (LLJ), rather persistent synoptic circulation, and high frequency of occurrence during summer time (Ferreira 2008). Previous studies (Seluchi et al. 2003; Saulo et al. 2004; among others) support the assumption that this kind of event is particularly sensitive to surface heating as well as enhanced soil moisture/surface temperature gradient, and are associated with heavy rainfall that is mostly concentrated over southeastern South America (SESA), at the exit region of the LLJ. So it is likely that this system is suitable to develop an understanding of the physical mechanisms involved in the soil moisture-rainfall feedback. Moreover, given that the selected situation is in close correspondence with the first principal component identified by Compagnucci and Salles (1997) in summer, enhanced understanding should aid in the description of a significant portion of the processes underlying land-atmosphere coupling during the warm season.

In order to show how soil moisture-precipitation-circulation interaction takes place, and to see the impact of soil wetness changes on this interaction, we designed a series of sensitivity studies which are described in section 2 . Besides addressing the aforementioned issues we also expect them to serve as first indications on how land use changes related with human activities affect weather. Following a detailed analysis of the case study and the experimental design (section 2), sections 3 and 4 are devoted to the examination of impacts on precipitation and circulation respectively, while main conclusions are summarized in section 5 . 


\section{Case study and model design}

Several circulation patterns can be clearly identified during the warm season in the vicinity of South America, including the well-documented intraseasonal sea-saw pattern (Nogués-Paegle and Mo, 1997). This pattern explains precipitation enhancement over the South Atlantic Convergence Zone (SACZ) in one phase and over Southeastern South America (SESA) in the opposite phase. The South America Low Level Jet (SALLJ) (Marengo et al. 2004; Vera et al. 2006a and references therein) tends to be more active in the latter phase, and is associated with a thermalorographic low pressure system, centered around $28^{\circ} \mathrm{S}$, immediately east of the Andes. This system, locally known as the Northwestern Argentina Low (NAL), helps to increase the meridional penetration of the SALLJ in such a way that precipitation at the exit region of the jet occurs over SESA (Salio et al. 2002, Saulo et al. 2004).

There are very few papers focusing in the NAL. This system was initially identified by Schwerdtfeger, (1950) and then studied by Lichtenstein (1980), who introduced the idea of "thermal-orographic" system to synthesize the main processes operating on the NAL. More recently, Seluchi et al. (2003) discussed the mechanisms associated with the NAL life cycle in two case studies, and Ferreira (2008) extended this analysis with a climatology of the NAL (manuscript in preparation). One interesting aspect of this low pressure system is that it is very sensitive to the surface energy budget, and also responds to orographic effects resulting from the interaction of the Andes with the progression of midlatitude baroclinic systems approaching South America. Seluchi et al. (2003) document large surface warming at NAL 
locations, which results from a succession of days with clear skies over an area characterized by very dry soils with shrub-type vegetation. The obvious dependence of surface warming on land-surface characteristics suggest that changes in surface conditions may significantly modify NAL strength and SALLJ intensity, through geostrophic response (Saulo et al. 2004a).

These results in combination with process-studies over North America, (Fast and Mc Corcle, 1990; Zhong et al. 1996; Paegle et al. 1996; and Wu and Raman, 1997) that show that the Great Plains low-level jet exhibits strong sensitivity to changes in soil moisture and land surface contrasts, provide partial motivation to analyze how changes in surface conditions may alter the LLJ and the associated precipitation over South America. With this objective in mind, we selected a NAL event, since it combines sensitivity to surface conditions with a well developed low level jet.

The selected NAL event occurred between January 29 and February 7, 2003 and has been previously documented by Saulo et al. (2004b), using an enhanced upper air network and special data obtained during a NOAA-P3 flight, available through the South America Low Level Jet field EXperiment (SALLJEX, Vera et al. 2006b). The Weather Research and Forecasting model (WRF) version 2.0 (Skamarock et. al. 2005) is used to perform all experiments in a domain centered over the area affected by the NAL and the SALLJ shown in Figure 1. Many experiments were carried out to define model settings in order to ensure a reasonable representation of this long lasting event. The model domain was adjusted to meet this requirement: for example, a domain encompassing all South America, did not provide a satisfactory representation of the 
system. The model was run in non-hydrostatic mode with $40 \mathrm{~km}$ resolution in the horizontal and 31 vertical levels. We utilize the Eta Grid-scale Cloud and Precipitation microphysics scheme, ( Ferrier et al. 2002); convection was parameterized using the Kain-Fritsch method (Kain 2004); and the Rapid Radiative Transfer Model (Mlawer et. al. 1997) and Dudhia (1989) scheme are used to represent radiative fluxes in long and short waves respectively. The YSU (Yonsei University, Hong and Pan, 1996) scheme was selected for parameterizing boundary layer processes and the NOAH Land Surface Model to represent surface processes (Chen and Dudhia 2000). All simulations were initialized on 29 January 2003 at 1200 UTC and run for 10 days. Initial and boundary conditions with $6 \mathrm{hr}$ intervals are derived from the NCEP-GDAS analysis. Land use categories employed by the WRF are those generated by the USGS (US Geological Survey Land Use/Land Cover System, Anderson et al. 1976). All experiments are listed in Table I; the only difference between them is their initial condition of soil wetness, the variable that represents moisture content in a soil column. The run initialized with GDAS soil wetness will be referred to as the control run (CTRL).

The experiment design is conceived to address the following questions: Is SESA precipitation modified by changes in soil wetness at regional scales? What kind of feedbacks, due to these changes, can be identified in the circulation at synoptic time scales?. Experiments E1 and E3 should help to answer these issues, since they correspond to $50 \%$ decrease/increase -respectively- of soil wetness over the model domain. Although these experiments are unrealistic in the sense that there are no foreseeable reasons to expect such changes to occur over such a large area, they are useful to identify possible linkages between soil states and the circulation. It should be 
stressed that soil moisture changes proposed here are similar to those applied in many sensitivity studies, like Zhong et al. 1996; Paegle et al. 1996; Gallus and Seagal 1999; Collini et al. 2008; among others.

We also wish to evaluate the impact of enhanced soil moisture gradients (drier to the west or moister to the east) on the LLJ and related precipitation. This goal motivates experiments E2 and E4 which are similar to E1 and E3 but with moisture changes bounded by two specific areas: drier conditions (E2) are limited to northwestern Argentina area while moister ones (E4) affect SESA (see Figure 1 to locate the sub-areas subject to these soil wetness changes). In particular, this last experiment could be considered representative of an increase in agricultural activity and associated irrigation over one of the regions with greater economic activity in South America. In this sense we cover, at least partially, an analysis of effects linked with human activities in a more realistic way.

In order to validate model performance we select specific variables whose representation is critical for the processes of interest to this study. Figure 2 shows sea level pressure evolution at La Rioja $\left(28^{\circ} \mathrm{S}, 66^{\circ} \mathrm{W}\right)$, a station located at the center of the NAL. This parameter is usually taken as a reference of NAL intensity (Seluchi et al. 2003). Surface pressure variability during the chosen NAL event is wellreproduced by the CTRL run, compared with GDAS analysis and observed data. This figure depicts two pressure fall cycles: one from January 29 to February 1, and the other from February 3 to February 7. In general, the CTRL run tends to underestimate the depth of the low pressure system. This can be more clearly appreciated with the aid of Figure 3 which combines sea level pressure, $950 \mathrm{hPa}$ winds and 500/950 hPa 
thickness fields at three different stages of the system evolution: maximum depth during the first cycle (0000 UTC, February $1^{\text {st }}$ ), initial phase of the second cycle (0000 UTC, February $3^{\text {rd }}$ ) and complete dissipation (1200 UTC February $7^{\text {th }}$ ). There is good agreement between model and GDAS fields; the NAL is correctly located (see the closed isobar with its center around $30^{\circ} \mathrm{S}, 66,5^{\circ} \mathrm{W}$ ) though underestimated, and the low level circulation is very-well reproduced. The typical patterns associated with the weak SACZ phase, which include the NAL, and the northerly wind enhancement in the central part of the continent and the Atlantic anticyclone located west of its mean position, are also well represented.

Thickness fields are useful to identify the thermal character of the system (Seluchi et al. 2003) and also to recognize the area with stronger gradient associated with the location of a quasi-stationary front. Both are reasonably well captured by the simulation. The northward progression of the front by February $7^{\text {th }}$ (Figure 3, lower panel) is accompanied by a retreat of the low pressure system from northwestern Argentina towards the area where it is maintained as the Chaco-low. This modification characterizes the end of a NAL event (see Seluchi et al. 2003 for a discussion of the differences between one system and the other).

The accumulated precipitation associated with the event is shown in Figure 4, which includes observations from available rain gauge network and model simulation. In general, there is good agreement, particularly regarding the area affected by heavy rain. Day by day inspection of simulated precipitation also denotes good agreement between observations and simulations (not shown). The CTRL run tends to produce light precipitation between February 3 and 4 , over the area around $27^{\circ} \mathrm{S}, 60^{\circ} \mathrm{W}$, where 
it was not observed. Over the SACZ region, the WRF model tends to overestimate precipitation.

In general, we consider that the event is well represented by the CTRL run and is useful to the extent we need to support the experimental design and the conclusions we may drive from the sensitivity studies.

3. Impact of soil wetness changes on precipitation

Our first objective is to show how variations in soil wetness initial condition modify accumulated precipitation. Figure 5 shows the differences between each experiment and the CTRL run. E1 and E3 lead to the expected results: decreased soil wetness produces less precipitation and vice versa. Differences take place over the areas where precipitation was simulated, with major changes over central and eastern Argentina, Uruguay, southern Brazil, a band north of $15^{\circ} \mathrm{S}$ and along the frontal area. In terms of relative importance (changes normalized by total simulated precipitation in the CTRL run, not shown) it can be noticed that larger impacts occur south of $20^{\circ} \mathrm{S}$, regardless of whether soil wetness has been decreased or increased with respect to the CTRL run. Our difference fields for E1 and E3 look rather similar to Collini et al. (2008) results (see their Figure 5), reinforcing our idea that this particular case is highly representative of an important component of the summertime variability.

The response to the localized sensitivity experiments is distinct from the regional ones, and one of the most interesting results is that the anomalies (Figure 5) 
affect similar locations irrespective of the areas where soil wetness is modified. In E2 the response is consistent with a shift in the precipitation field, while in E4 there is a localized increase in rain centered over Uruguay, presumably associated with enhanced evaporation, combined with a shift in precipitation. Neither E2 nor E4 generate impacts over the SACZ precipitation region.

To identify the pathways for land-atmosphere interactions it is useful to analyze the day-by-day evolution of soil wetness, precipitation and Convective Available Potential Energy (CAPE). The area average evolution of these fields over the box indicated in Figure 5 is shown in Figure 6. This box is representative of the area where the sensitivity is relatively large in all experiments. It is of interest to point out that area average wilting point and saturation values are 0.088 and $0.498 \mathrm{~m}^{3} \mathrm{~m}^{-3}$ respectively, thus denoting that the experiments modify soil wetness contents between reasonable values. Splitting of precipitation in its convective and large scales components follows Pan and Elthair (2001) who showed that the convective portion was much more sensitive to soil moisture changes than the large scale one. As they state, convective rainfall in wet runs is facilitated due to two positive effects: lower cloud base and CAPE increases through low level moistening. In contrast, dry runs, though warmer, result in very deep boundary layers and lower CAPE.

Figure $6 \mathrm{a}$ shows the evolution of soil wetness for all the experiments. Soil moisture memory decreases with time, as expected: after 10 days of simulation, soil wetness differences become smaller, and all the experiments tend to the CTRL run. This is more evident for E2, E3 and E4 while in E1 the anomalous conditions appear to be more persistent. Given that soil wetness variations are hard to perceive, we 
plotted their anomalies (i.e. for each experiment we took the mean value and subtracted it from the actual value), which are shown in Figure 6b. Besides a short adjustment period, there can be recognized a tendency of soil moisture to decrease up to February $2^{\text {nd }}$ and then a distinct phase characterized by continued increase.

The first question is how soil wetness changes drive precipitation changes and how precipitation modulates soil wetness. We address this issue with the aid of Figures $6 \mathrm{c}$ and $\mathrm{d}$. Changes in soil moisture affect the large scale and the convective portion of precipitation; however, given the small amount of large scale precipitation involved (rain rates below $1 \mathrm{~mm} \mathrm{day}^{-1}$ ), the stronger impacts are associated with the convective portion of precipitation, as expected. If we compare E3 with E1 in Figure $6 c$, it is clear that convective precipitation starts earlier when soil wetness is higher over the area. Besides the marginal precipitation in the first few days, the most important differences appear by February 2 (both in convective and large scale portions). This helps to explain soil wetness behavior from the beginning of the model run: when there is no rain, soil moisture evaporates, especially in experiments with increased soil wetness (E3 and E4 values decrease substantially, as seen in Figure 6c). Just after this time, all the experiments except E1 show the start of heavier precipitation, and soil wetness responds rapidly, with larger increases in close correspondence to larger rainfall rates. There is a sustained recuperation of soil wetness amounts from February $3^{\text {rd }}$ which is more evident in the drier runs.

With regard to CAPE variability (Figure 6e) it can be seen that experiments with higher CAPE have more convective rainfall (Figure 6c). However, given similar CAPE amounts from the beginning of the experiment until February $3^{\text {rd }}$, significant 
precipitation does not start until February $2^{\text {nd }}$. This indicates that changes in the circulation may have occurred between these dates. The diurnal cycle of CAPE increasing between 1200 UTC and 0000 UTC, and decreasing afterwards- is very similar for all the experiments except for E1. In terms of CAPE evolution, there is also a strong similarity between CTRL, E2, E3 and E4 from 1200 UTC, February 3 to the end of the simulation (i.e. from the second cycle). CAPE in E1 does not reach 400 $\mathrm{J} \mathrm{kg}^{-1}$ until February 3: this increase is accompanied by light but sustained convective precipitation which explains the important recuperation of soil wetness between February 4 and the end of the model run. This is denoted by the increase of soil wetness rate during this last period. However CAPE in E1 remains lower than that of the other experiments during the entire integration. The particular diurnal cycle of CAPE in E1 is mostly explained by $2-\mathrm{m}$ specific humidity variability that tends to maximize between 1200 and 1500 UTC -not shown-.

Up to this point we can recognize the following links: higher soil wetness produces larger CAPE and triggers earlier convective precipitation. This is a common feature among CTRL, E2, E3 and E4. Differences between these experiments -at least until February $5^{\text {th }}$ - can be understood as a direct feedback between soil wetness amount and precipitation response: higher soil wetness leads to larger CAPE and associated precipitation. Availability of surface moisture is maintained through this positive feedback between precipitation and surface conditions, leading to enhanced areal precipitation that characterizes all the experiments with normal or augmented moisture over SESA. This feedback, but with opposite sign is evident in the dry run E1. However this negative coupling is overcome by an external forcing (in this case, of synoptic scale) that increases CAPE -after February $3^{\text {rd }}$ - and leads to marginal 
precipitation which increases the surface moisture, and changes E1 tendency, as a response to CAPE growth and the associated precipitation occurrence. After 7 days of simulation (by February 6) CAPE is above $800 \mathrm{~J} \mathrm{~kg}^{-1}$ even in E1, with peak values related to moister runs that reach $1600 \mathrm{~J} \mathrm{~kg}^{-1}$, while the amount of precipitation is considerable less for the drier runs.

4. Impact of soil wetness changes in the circulation

In the previous section we described the impact on precipitation and suggested local feedbacks that could aid in understanding the simulated behavior. We also need to understand if there is an advective contribution to rain that is being modified by soil wetness changes. To address this, we look at low level circulation, moisture convergence and the water budget integrated during the whole run. Unlike precipitation, it is not equally informative to simply average wind anomalies over the 10 day period. After analyzing the day by day evolution of the anomalies, we decided to synthesize them through their mean value at a particular UTC time. In this way we retain the major changes in circulation that occur at nighttime/early morning and are responsible for enhanced convergence at the exit region of the low level jet (Saulo et al. 2004; Nicolini and Saulo 2006; among others). Figure 7 shows the mean wind anomaly at $0900 \mathrm{UTC}$ (approximately $0600 \mathrm{AM}$ local time at $55^{\circ} \mathrm{W}$ ) for E1 and E3. We have selected this UTC time because it depicts the highest anomaly values, while being representative of the patterns observed at, 0300, 0600 and even 1200 UTC. The largest wind anomalies are evident in E1, followed by E3. Neither E2 nor E4 show consistent wind anomalies on any day and/or UTC time (not shown). An interesting 
result is that circulation changes occur over an area that matches northerly wind core and frontal convergence regions, and does not fully coincide with the precipitation anomaly area (compare Figures $7 \mathrm{a}$ and $\mathrm{b}$ with Figure 5). For the dry run, circulation anomalies over central portion of the domain are coherent with a geostrophic response to a deepened thermal low, what can be inferred looking at the evolution of sea level pressure at La Rioja (Figure 2). E1 simulates lower pressures throughout the whole run, at least compared with the other model runs. The opposite holds for E3, which tends to simulate the weakest NAL among the experiments, and is compatible with southerly anomalies close to the Andes, over central Argentina. Temporal evolution of wind changes - only for E1-CTRL- averaged over the same box used for previous analyses is shown in Figure 8. This figure illustrates that, immersed in a sustained northerly wind current, that maximizes between 0300 and 0900 UTC (see contours), there are pulses of northerly anomalies that tend to reinforce and deepen the low level jet. This is the only experiment where wind changes are evident on a day by day basis.

In order to synthesize the impact of soil wetness changes in the circulation and the precipitation, we calculated the water vapor balance equation following Rasmusson (1967), expressed as:

$$
\frac{\partial W}{\partial t}+\nabla \bullet Q=E-P
$$

which states that changes in atmospheric moisture storage (W) in a column, are due to vertically integrated water vapor flux divergence $(\nabla \bullet Q)$, evapotranspiration from the surface (E) and precipitation (P). Vertical integration has been done between 1000 $\mathrm{hPa}$ and $100 \mathrm{hPa}$. Usually, when integrated over a long period (more than a month) 
the first term in Eq. (1) is negligible, but, in our case, temporal variations of W can not be disregarded. Figure 9 shows the integral for the whole simulation period of all the terms as represented by the CTRL run, and the corresponding differences with E1 and E3 (E2 and E4 are not shown, since the anomaly fields are small). Figures 9a and b show that, during this event, there is good correspondence between precipitation and moisture flux convergence fields. Northeastward of the $30 \mathrm{~mm}$ E-isopleth (Figure 9b), evaporation has also a substantial contribution. From the differences fields, it can be noted that less precipitation in E1 over central and eastern Argentina, Uruguay and southern Brazil is mostly explained by less evaporation, combined with decreased moisture convergence. The response in moisture convergence suggests that moisture reduction plays a dominant role in this field, compared with wind, that tends to increase convergence in a latitudinal band around $34^{\circ} \mathrm{S}$ (see Figure 7a). Over the northern portion of the domain (part of Brazil, Perú and Bolivia), evaporation is less related with precipitation decreases, which seem to be mostly explained by a reduction in moisture convergence. On the other hand, changes of precipitation in E3, closely follow those of increased moisture flux convergence differences, combined with a homogeneous increase in evaporation most apparent over Argentina. The other interesting signature in $\mathrm{E} 3$ comes from $\mathrm{W}$ contribution that is negative, meaning that E3 has relatively higher rain efficiency than the control (less liquid water content is left in the column).

Over adjacent oceans there appear to be two distinct effects on E1: southward displacement of convergence seems to explain the resultant positive precipitation anomaly (south of Buenos Aires) and, increased W, combined with weakened moist convergence, aid in explaining the negative anomaly over the Atlantic (the one 
centered over $38^{\circ} \mathrm{S}, 47^{\circ} \mathrm{W}$ ). A signature compatible with meridional displacement of convergence areas can also be noticed in E3. In general, the location of anomalous convergent areas is highly correlated with precipitation anomalies. Exceptions to this are E1 negative moisture flux divergence anomalies over northern Argentina, Paraguay and southern Bolivia. This particular area exhibits a precipitation minimum in all the experiments.

\section{Summary and conclusions}

The present experiments show sensitivity to soil wetness changes as measured by precipitation variations. In turn, soil wetness rapidly reacts to rainfall, in such a way that after 10 days of simulation, the anomalous initial conditions tend to weaken. This response is not uniform over the model domain, and is more evident over SESA. The pathways relating soil-atmosphere interactions can be more easily tracked with the aid of E1 and E3: less (/more) soil wetness reduces (/enhances) CAPE so that precipitation -particularly its convective portion- is decreased (/increased). This positive feedback is maintained during the first five days of simulation (i.e. until February 3 approximately) and corresponds to the first cycle of NAL pressure fall and the transition stage between the two cycles. The second phase is characterized by a stronger synoptic forcing, as suggested by the cleaner pressure fall cycle denoted in the evolution of sea level pressure at La Rioja, which also includes NAL decay by February 7, 1200 UTC (see the post-frontal anticyclone reaching central Argentina at this time in Figure 3). This circulation is strong enough to start precipitation in E1, even under less favorable CAPE preconditioning, and to recover soil moisture deficits 
by the end of the simulation. Day by day inspection of the precipitation evolution (not shown) corroborates this analysis, and provides further details: the main difference between E1 and E3 is that in E3 there is strong pre-frontal activity over Buenos Aires and central Argentina on February $2^{\text {nd }}$ not simulated by E1. This delay in convective triggering is crucial to understand soil influences at these time scales.

Looking at the circulation changes, it is clear that low level wind is more reactive to a reduction in soil wetness than to an increase of this parameter, and the response is as expected: an enhanced northerly wind which results from a deepened NAL under dry conditions. The stronger northerlies in E1 can also explain the southward shift of the frontal precipitation, evident at the maritime portion of the front. The wind response in E3 is weaker, compatible with reduced northerlies over central Argentina (i.e associated with weaker NAL) and at the frontal area that can be related with the northward location of the precipitation maximum associated with the front.

The combined effects of changes in the circulation and in local stratification induced by soil wetness modifications, through variations in evaporation and CAPE, can be synthesized as follows: there is a dynamical response in the dry run, essentially associated to a stronger LLJ, that involves decreased convergence in the northwestern portion of the domain and enhanced convergence at the exit region of the LLJ -which is displaced towards the south-. This dynamical response is not as robust as that induced by less (/more) evaporation and drier (/moister) low level air masses that result from lower (/higher) soil wetness. These modifications also alter the stratification, in agreement with what has been found by Pan an Elthair (2001). As a 
consequence, the moisture flux convergence pattern in E1 (/E3), though different from the CTRL run, maintains its main features, but modulated by less (/more) moisture availability. As a result, precipitation is more coherently modified where CAPE and moisture flux convergence variations mutually reinforce.

It is interesting to contrast these results with others obtained under different frameworks and/or motivations. For example, areas with larger sensitivity in our study coincide with areas highlighted by Dirmeyer et al. (2009) as having soil moisture controlling evapotranspiration, plus a climate regime tending to maintain soil moisture anomalies, which in turn become larger through recycling (see their Figure 6). Also, that study identifies these areas as having relatively short soil moisture memory, concluding that prediction may benefit from careful initialization of soil conditions at forecast ranges below 30 days. This is in agreement with our results, since we found important differences in precipitation arising from changes in the initial soil moisture condition, which, in turn, are reinforced during a limited time period, and then tend to reduce.

We obtained somewhat different results from Collini et al. (2008), particularly with respect to wind changes during dry events, which, in our case, are more evident and extend to the surface. Also, they did not analyze the wet runs, since the impact was less coherent over their area of interest. Still their discussion on the mechanisms that may explain their results are in complete agreement with what we found in our case study. 
With regard to the interpretation of E2 and E4, we consider that a deeper analysis than the one performed here is needed. As already mentioned, the impact is only detectable in the accumulated precipitation, and the pattern of rain changes is not radically different between them. This is probably due to the fact that the areas selected to modify the soil condition, and the modification introduced (lowering soil wetness in E2 and increasing it in E4) are such that the final impact is not substantially different. We speculate that this may be attributed to a natural response of the system: no matter how we modify the initial condition we obtain similar perturbations. Still, this hypothesis needs more experimentation. What can be stated from this preliminary analysis is that, at synoptic time scales, soil wetness reduction over northwestern Argentina and soil wetness increase over SESA perturb the associated precipitation in a similar way (both regarding the area and the type of modification), with a slight preference for the latter to increase it (according to the area averages presented in Figure 6). This result leaves a warning on possible impacts of enhanced irrigation over SESA agricultural area.

The current South American study is done in the spirit of earlier short-tomedium range deterministic forecasts for North America (i.e. Trier et al. 2008; Gallus and Seagal 1999 and Zhong et al. 1996) and it therefore emphasizes one case with relatively large soil moisture changes. From this case study it can be inferred that soil moisture has a significant impact on precipitation, and this impact becomes evident when the areas where precipitation is occurring are clearly identified. This denotes the value added by analyzing individual cases. Most of the changes in precipitation are due to changes in the availability of moisture at low levels. Modifications in the circulation are less evident and need even a more careful analysis in order to be 
recognized. Soil memory over the area of study is weak (compared with other regions) but enough to alter precipitation in a persistent way. For this reason, it is considered that this study further supports the importance of precise initial soil conditions in achieving maximum predictability at short and medium ranges.

Acknowledgments:

This study has been supported by the following projects: GC06-085 from NOAA/OGP/CPPA, ANPCyT PICT 2004 25269, UBACyT X204, CONICET PIP 112-200801-00399, 490225/2008-0 (Prosul) and 305302/2006-0 from CNPq. 
References

Anderson J. R., E. E. Hardy, J. T. Roach and R. E. Witmer, 1976: A land use and land cover classification system for use with renote sensor data. U.S. Geological Survey Professional Paper 964. Government Printing Office, Washington. 41 pp.

Chen, S.-H., and J. Dudhia, 2000: Annual report: WRF physics, Air Force Weather Agency, 38pp.

Collini E. A., E. H. Berbery and Barros V., 2008: How Does Soil Moisture Influence the Early Stages of the South American Monsoon?. J. Climate; 21, 2,195-213.

Compagnucci, R.H., Salles, M.A., 1997: Surface pressure patterns during the year over southern. South America. Int. J. Climatol., 17, 635-653.

Dirmeyer, P.A., C.A. Schlosser, and K.L. Brubaker, 2009: Precipitation, Recycling, and Land Memory: An Integrated Analysis. J. Hydrometeor., 10, 278-288.

Dudhia J., 1989: Numerical Study of Convection Observed during the Winter Monsoon Experiment Using a Mesoscale Two-Dimensional Model. J. Atmos Sci. 46, $3077-3107$

Fast J. and Mc Corcle M., 1990: A two dimensional numerical sensitivity study of the great plains low level jet. Mon. Wea. Rev., 118, 151-163.

Ferreira, 2008: Causas y variabilidad de la Depresión del Noroeste Argentino e Impactos sobre los Patrones Regionales de Circulación (Causes and variability of the Northwestern Argentina Low and its impact over the regional circulations patterns). Ph.D. Dissertation. 177 pp. [Available from Departamento de Ciencias de la Atmosfera, Ciudad Universitaria (1428) Buenos Aires, Argentina].

Ferrier, B. S., Y. Jin, Y. Lin, T. Black, E. Rogers, and G. DiMego, 2002: Implementation of a new grid-scale cloud and precipitation scheme in the NCEP Eta 
model. 15th Conf. on Numerical Weather Prediction. San Antonio, Amer. Meteor. Soc., 280-283.

Gallus, W.A., and M. Segal, 1999: Diabatic Effects on Late-Winter Cold Front Evolution: Conceptual and Numerical Model Evaluations. Mon. Wea. Rev., 127, $1518-1537$.

Grimm, A., J. S. Pal, and F. Giorgi, 2007: Connection between Spring Conditions and Peak Summer Monsoon Rainfall in South America: Role of Soil Moisture, Surface Temperature, and Topography in Eastern Brazil. J. Climate, 20, 5929-5945.

Hong S. and H. Pan, 1996: Nonlocal Boundary Layer Vertical Diffusion in a Medium-Range Forecast Model. Mon. Wea. Rev, 10, 2322-2339.

Kain J. S., 2004: The Kain-Fritsch Convective Parameterization: An Update. J. Appl. Meteor.. 43, 170-181.

Lichtenstein E.R., 1980: La Depresion del Noroeste Argentino (The Northwestern Argentina Low). Ph.D. Dissertation. 223 pp. [Available from Departamento de Ciencias de la Atmosfera, Ciudad Universitaria (1428) Buenos Aires, Argentina]. Marengo, J., W. R. Soares, C. Saulo and M. Nicolini, 2004: Climatology of the LowLevel Jet East of the Andes as Derived from the NCEP-NCAR Reanalyses: Characteristics and Temporal Variability. J. Climate, 17, 2261-2280.

Mlawer, E. J., S. J. Taubman, P. D. Brown, M. J. Iacono, and S. A. Clough, 1997: Radiative trans-fer for inhomogeneous atmosphere: RRTM, a validated correlated-k model for the long-wave. J. Geophys. Res.: 102, D14, 16663-16682.

Nicolini, M. and A. C. Saulo, 2006: Modeled Chaco low-level jets and related precipitation patterns during the 1997-1998 warm season. Meteor. nd Atmos. Phys. 94, 1-4, 129-143. doi: 10.1007/s00703-006-0186-7 
Nogués-Paegle, J., and K. C. Mo, 1997: Alternating wet and dry conditions over South America during summer. Mon. Wea. Rev., 125, 279-291.

Paegle J., K. C. Mo, J. Nogués-Paegle., 1996: Dependence of simulated Precipitation on Surface evaporation during the 1993 United States Floods. Mon. Wea. Rev., 124, 345-361.

Pal, J.S., and E. A. B. Eltahir, 2001: Pathways Relating Soil Moisture Conditions to Future Summer Rainfall within a Model of the Land-Atmosphere System. J. Climate, 14, 1227-1242.

Rodell, M., P. R. Houser, U. Jambor, J. Gottschalck, K. Mitchell, C. J. Meng, K. Arsenault, B. Cosgrove, J. Radakovich, M. Bosilovich, J. K. Entin, J. P. Walker, D. Lohmann, and D. Toll, 2004: The Global Land Data Assimilation System. Bull. Amer. Meteor. Soc., 85 (3), 381-394.

Saulo A.C, M. E. Seluchi and M. Nicolini, 2004a: A Case Study of a Chaco LowLevel Jet Event: Mon. Wea. Rev. 132, 11, 2669-2683.

— , L. Ferreira, J. Mejia and M. Seluchi, 2004b: Description of the Termal Low Characteristic using SALLJEX Special Observations. Clivar Exchanges, 9, 9-10 and 17.

Salio, P., M. Nicolini y A.C. Saulo, 2002: Chaco Low-Level Jet Events Characterization During the Austral Summer Season by ERA Reanalysis. J. Geophys. Res - Atmos. 107, D24, 4816, doi: 10.1029/2001JD001315

Schwerdtfeger, W.C., 1950: La depresión térmica del Noroeste Argentino. Anales de la Sociedad científica Argentina. Tomo CL, Buenos Aires, 15 pp.

Seluchi, M., A.C. Saulo, M. Nicolini, y P. Satyamurty, 2003: The Northwestern Argentinean Low: A Study of Two Typical Events. Mon. Wea. Rev., 131, 2361-2378. 
Skamarock, W. C., J. B. Klemp, J. Dudhia, D. O. Gill, D. M. Barker, W. Wang, and J.

G. Powers, 2005: A description of the Advanced Research WRF Version 2. NCAR Tech Notes-468+STR . 100pp

Trier, S.B., F. Chen, K.W. Manning, M.A. LeMone, and C.A. Davis, 2008: Sensitivity of the PBL and Precipitation in 12-Day Simulations of Warm-Season Convection Using Different Land Surface Models and Soil Wetness Conditions. Mon. Wea. Rev., 136, 2321-2343.

Vera, C., W. Higgins, J. Amador, T. Ambrizzi, R. Garreaud, D. Gochis, D. Gutzler, D. Lettenmaier, J. Marengo, C.R. Mechoso, J. Nogues-Paegle, P.L.S. Dias, and C. Zhang, 2006a: Toward a Unified View of the American Monsoon Systems. J. Climate, 19, 4977-5000.

Vera, C.; J. Baez; M. Douglas; C. B. Emmanuel; J. Marengo; J. Meitin; M. Nicolini; J. Nogues-Paegle; J. Paegle; O. Penalba; P. Salio; C. Saulo; M. A. Silva Dias; P. L. Silva Dias; and E. Zipser, 2006b: The South American Low-Level Jet Experiment (SALLJEX). Bull. Am. Met. Soc, 87, 63-77.

Wu Y. and S. Raman, 1997: Effect of land use pattern on the development of low level jets. J. Applied Met, 36, 573-590.

Xue, Y., F. De Sales, W. P. Li, C. Mechoso, C. Nobre, H. Juang, 2006: Role of Land Surface Processes in South American Monsoon Development. J. Climate, 19, 741762.

Zhang, 2006: Toward a Unified View of the American Monsoon Systems. J. Climate, 19, 4977-5000.

Zhong S., J. D Fast, X. Bien, 1996: A case study of the Great Plains Low Levels Jet Using Wind Profiler Network Data and high resolution mesoscale model. Mon. Wea. Rev., 124, 785-805. 
Figure Captions

Figure 1: Model domain (shaded) and soil wetness initial condition (contours in $\mathrm{m}^{3} \mathrm{~m}^{-}$ ${ }^{3}$ ) for the control run, on 29 January 2003 12UTC. Ellipses indicate areas where soil wetness was modified in E2 and E4 (left and right ellipses, respectively). The position of La Rioja station is also indicated.

Figure 2: Sea level pressure temporal evolution at La Rioja. Solid line represents the observation; filled squares: GDAS analysis; filled circles: CTRL run; open circles: E1 run and open triangles: E3 run.

Figure 3: Mean sea level pressure (contours, in hPa), 500/950 thickness (shaded, in m) and $950 \mathrm{hPa}$ winds (vectors, $\mathrm{m} \mathrm{seg}^{-1}$ ) at $0000 \mathrm{UTC}$, February $1^{\text {st }}$ (first row), 0000 UTC, February $3^{\text {rd }}$ (middle row) and 1200 UTC, February $7^{\text {th }}, 2003$ (last row). Left column: CTRL simulation; right column: GDAS analysis.

Figure 4: a) Rain gauge data and b) CTRL run accumulated precipitation between 1200 UTC January 29 and 1200 UTC February 7 (in mm). White boxes indicate grid areas where data is unavailable.

Figure 5: Accumulated precipitation differences (in $\mathrm{mm}$ ) between each experiment and the control run. The box in the first panel indicates the area where averages have been performed.

Figure 6: a) Soil wetness $\left(\mathrm{m}^{3} \mathrm{~m}^{-3}\right)$, b) soil wetness anomalies $\left(\mathrm{m}^{3} \mathrm{~m}^{-3}\right)$, c) daily accumulated convective precipitation $(\mathrm{mm})$, d) daily accumulated large scale precipitation (mm) and e) maximum CAPE $\left(\mathrm{J} \mathrm{kg}^{-1}\right)$ area averaged over the box indicated in Figure 5.

Figure 7: Mean wind anomalies in $\mathrm{m} \mathrm{s}^{-1}$ at 0900 UTC for a) E1-CTRL and b) E3CTRL. 
Figure 8: Mean meridional wind speed $\left(\mathrm{ms}^{-1}\right)$ vertical cross section for the CTRL run (contours) and its anomaly (E1-CTRL, shaded), averaged in the box indicated in Figure 5 .

Figure 9: Temporally integrated water vapor balance equation terms $(\mathrm{mm})$ for the whole run. CTRL run (a and b) and differences E1-CTRL (c and d) and E3-CTRL (e and f). Left columns: moisture flux divergence (shaded) and moisture storage change (contours). Right columns: precipitation (shaded) and evaporation (contours). 
Table I

\begin{tabular}{|l|l|}
\hline & Soil wetness Initial condition \\
\hline E1 & $50 \%$ reduction over the entire domain \\
\hline E2 & $50 \%$ reduction over NW Argentina \\
\hline E3 & $50 \%$ increase over the entire domain \\
\hline E4 & $50 \%$ increase over SESA \\
\hline CTRL & NCEP/GDAS analysis \\
\hline
\end{tabular}

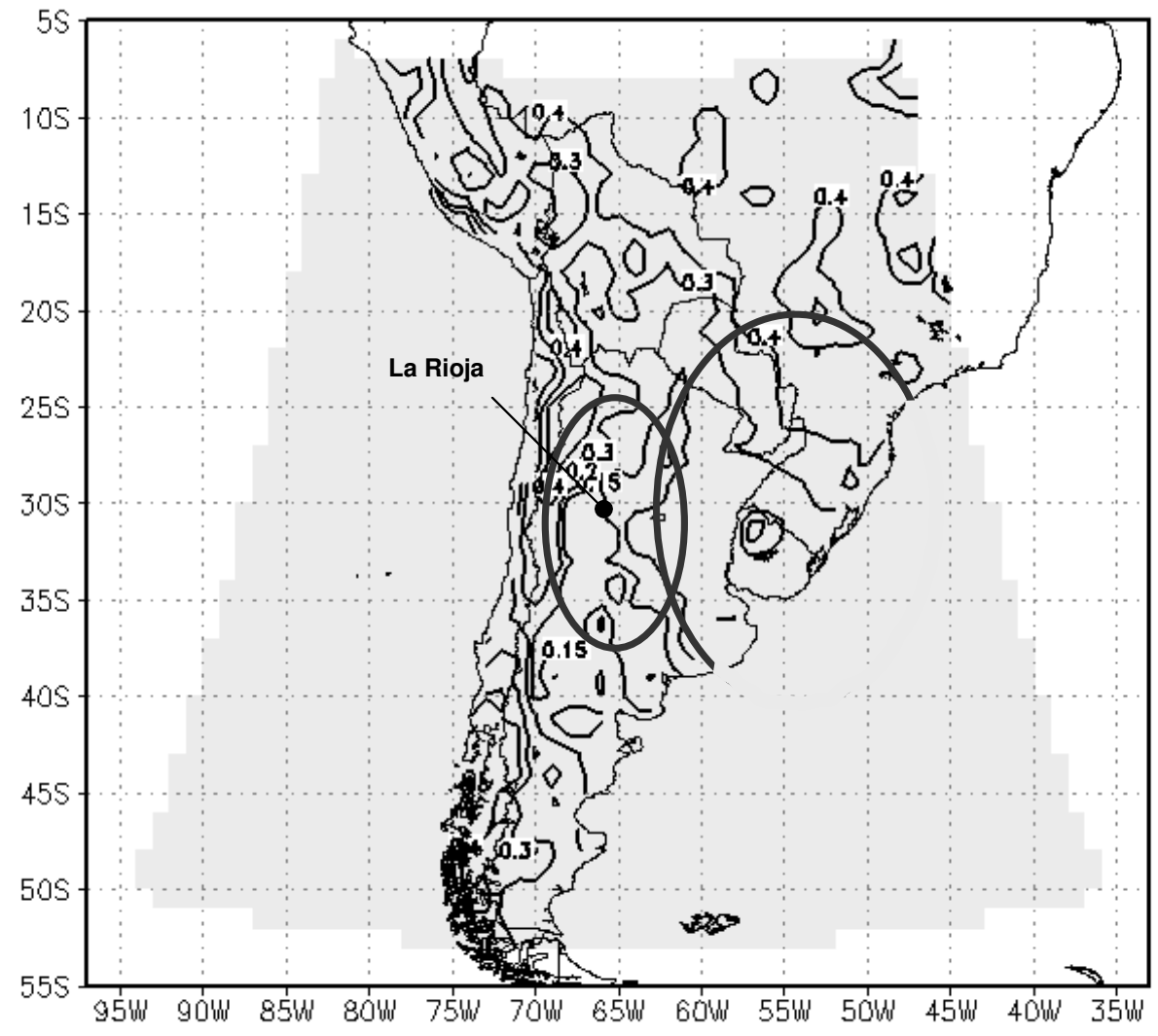


Figure 1: Model domain (shaded) and soil wetness initial condition (contours in $\mathrm{m}^{3} \mathrm{~m}$ ${ }^{3}$ ) for the control run, on 29 January 2003 12UTC. Ellipses indicate areas where soil wetness was modified in E2 and E4 (left and right ellipses, respectively). The position of La Rioja station is also indicated.

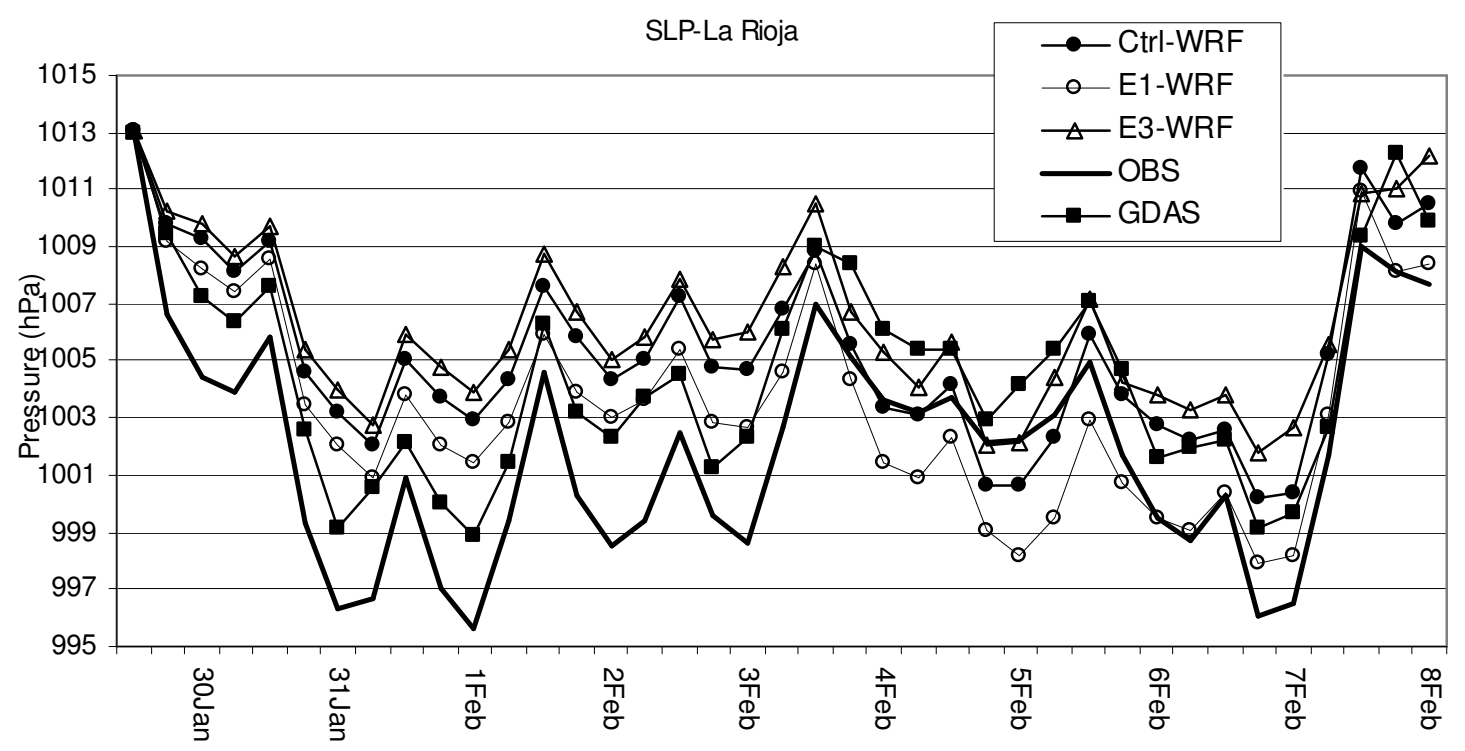

Figure 2: Sea level pressure temporal evolution at La Rioja. Solid line represents the observation; filled squares: GDAS analysis; filled circles: CTRL run; open circles: E1 run and open triangles: E3 run. 

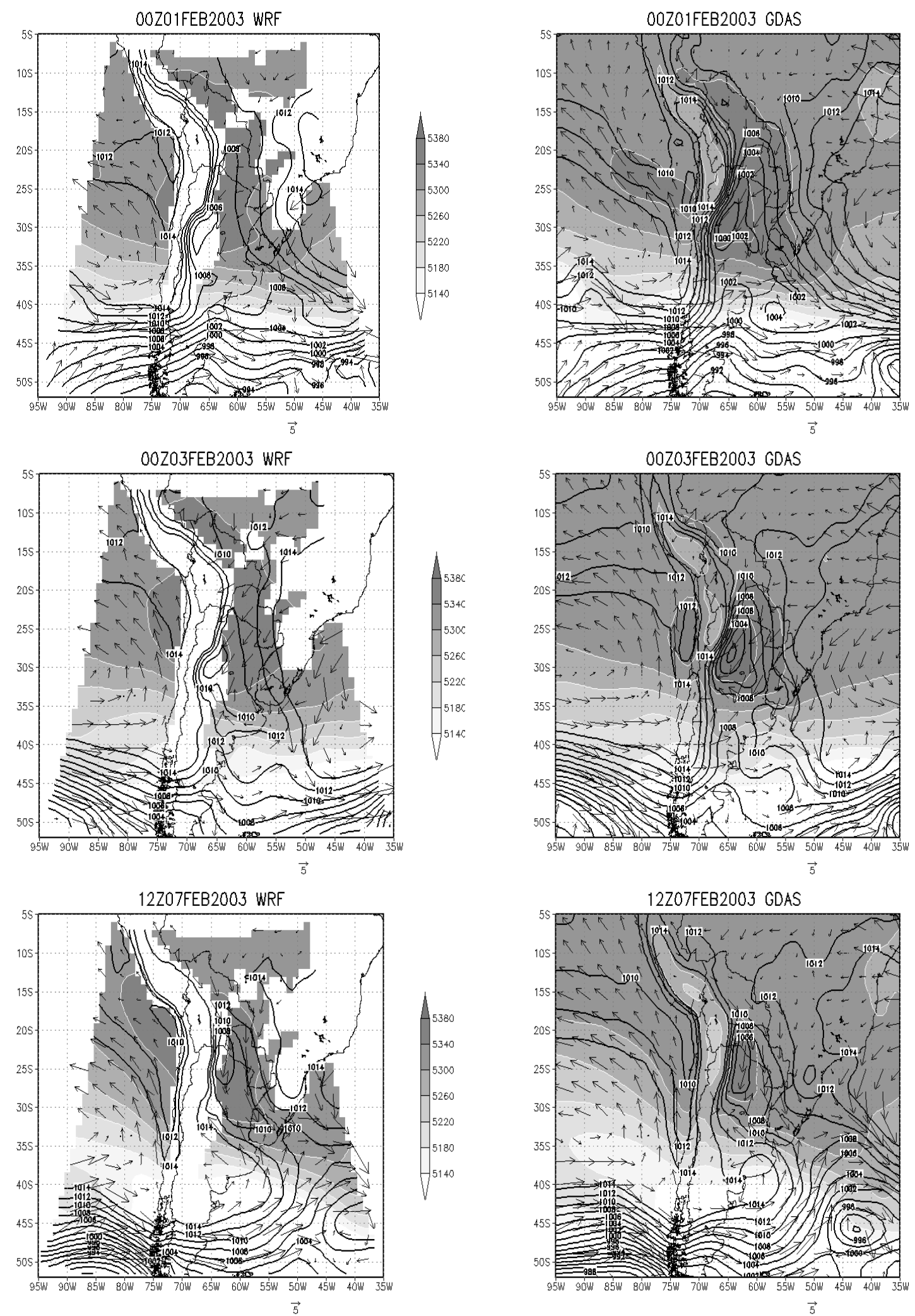
Figure 3: Mean sea level pressure (contours, in hPa), 500/950 thickness (shaded, in $\mathrm{m}$ ) and $950 \mathrm{hPa}$ winds (vectors, $\mathrm{m} \mathrm{seg}^{-1}$ ) at 0000 UTC, February $1^{\text {st }}$ (first row), 0000 UTC, February $3^{\text {rd }}$ (middle row) and 1200 UTC, February $7^{\text {th }}, 2003$ (last row). Left column: CTRL simulation; right column: GDAS analysis.

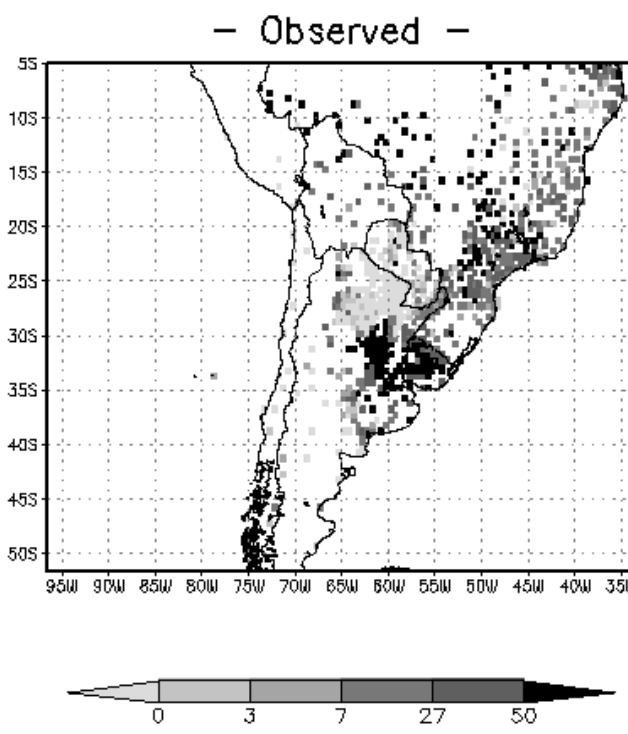

(a)
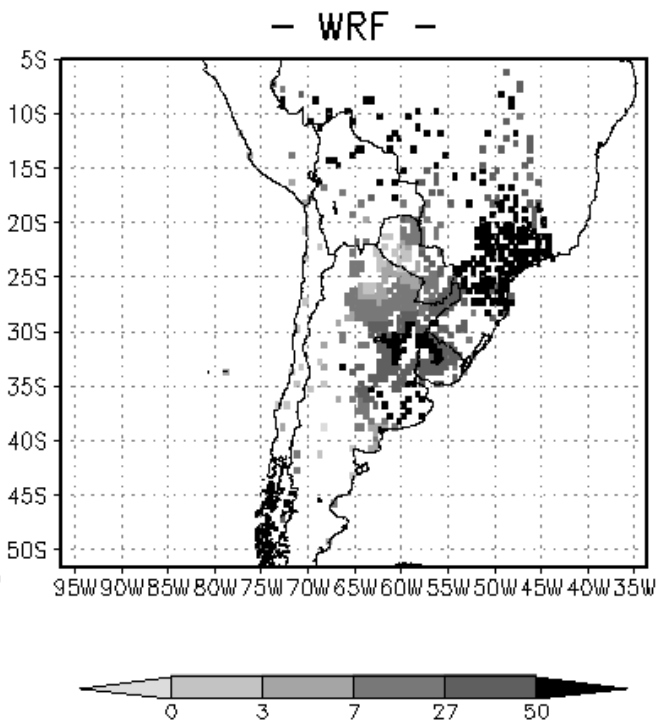

(b)

Figure 4: a) Rain gauge data and b) CTRL run accumulated precipitation between 1200 UTC January 29 and 1200 UTC February 7 (in mm). White boxes indicate grid areas where data is unavailable. 

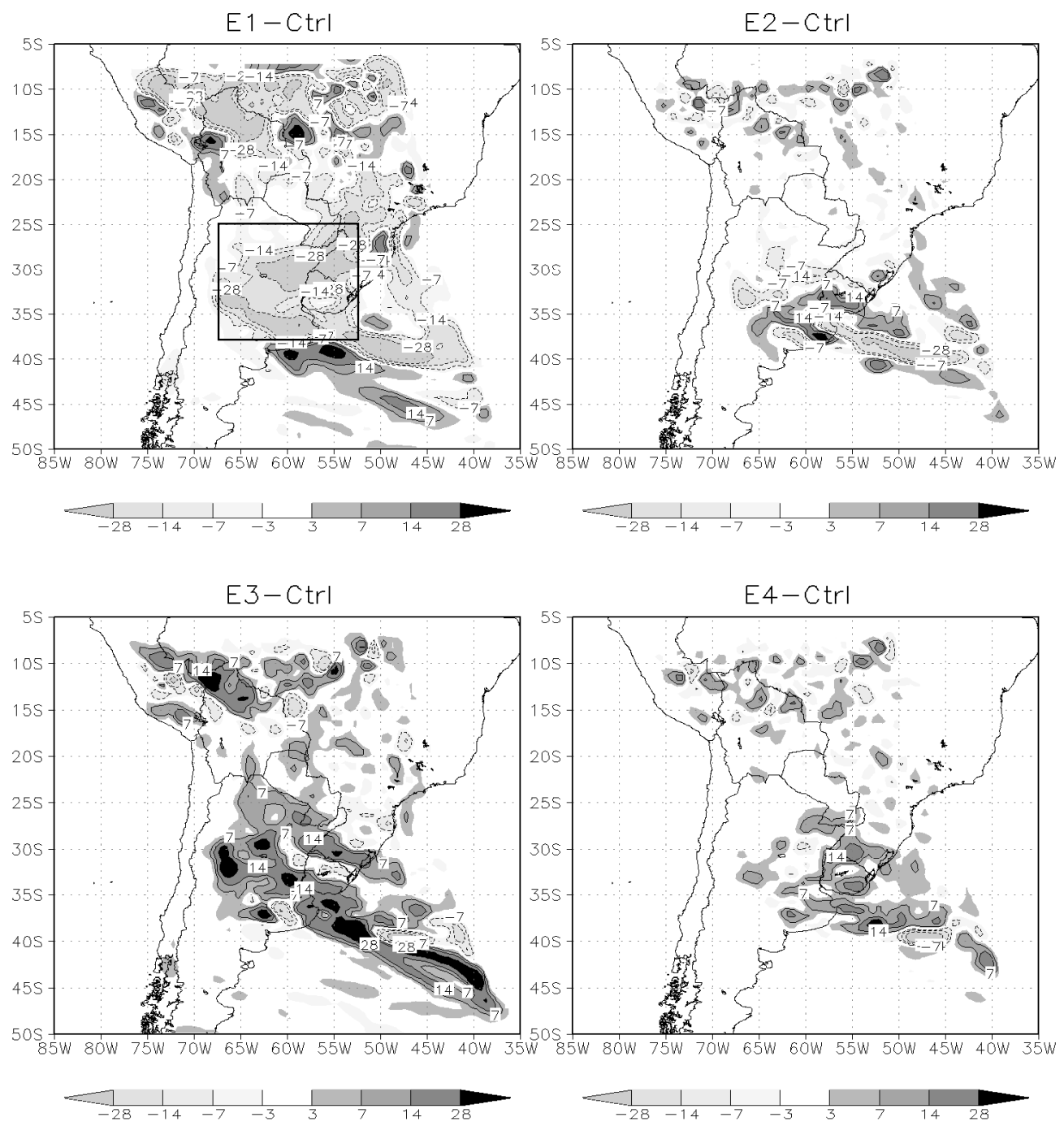

Figure 5: Accumulated precipitation differences (in $\mathrm{mm}$ ) between each experiment and the control run. The box in the first panel indicates the area where averages have been performed. 
a)

Soil wetness

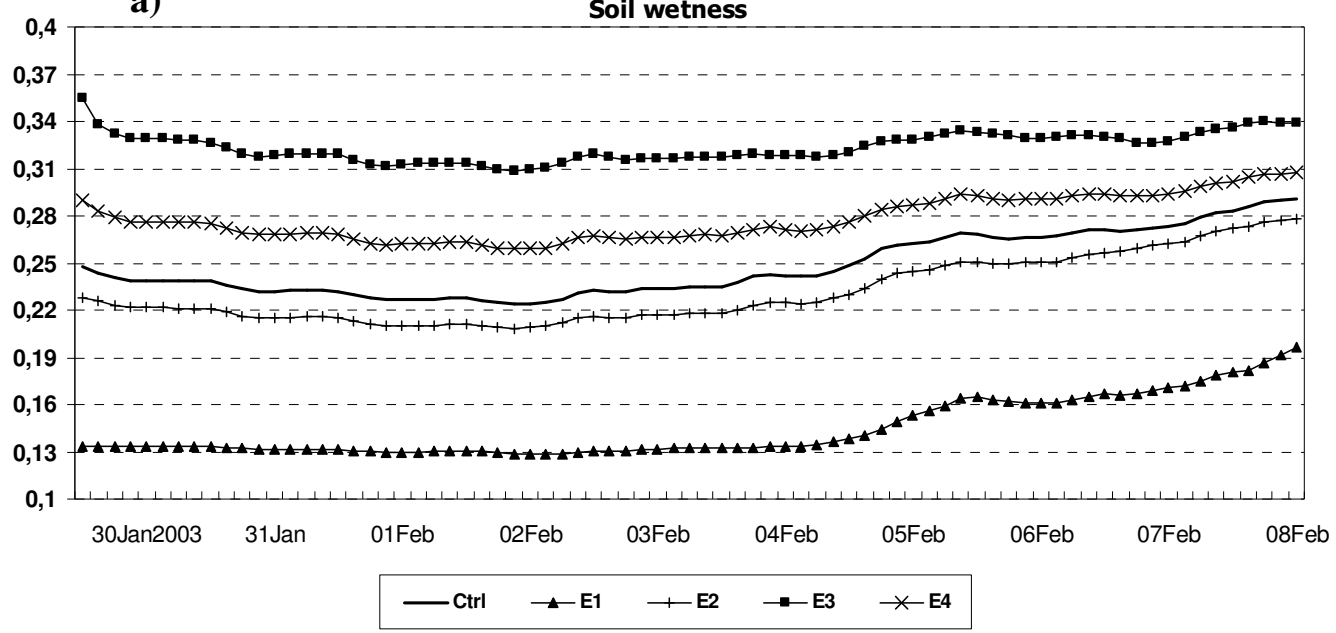

b)

Soil wetness

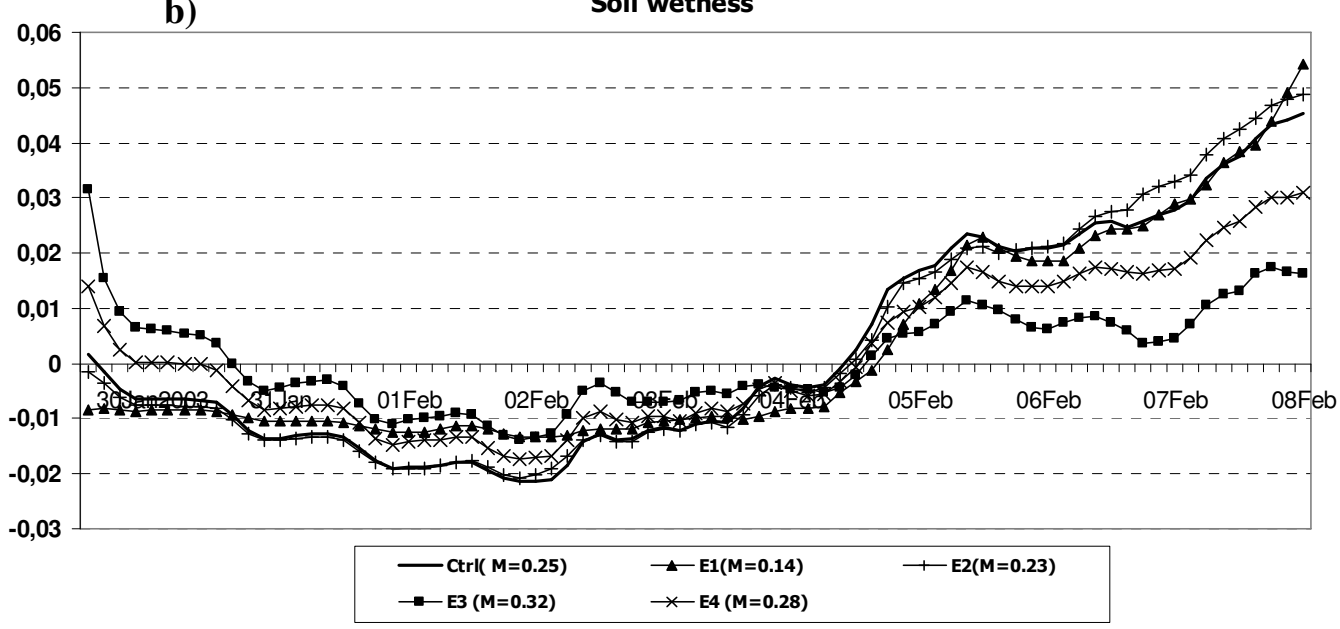

Figure 6: a) Soil wetness $\left(\mathrm{m}^{3} \mathrm{~m}^{-3}\right)$, b) soil wetness anomalies $\left(\mathrm{m}^{3} \mathrm{~m}^{-3}\right)$, c) daily accumulated convective precipitation $(\mathrm{mm}), \mathrm{d}$ ) daily accumulated large scale precipitation $(\mathrm{mm})$ and e) maximum CAPE $\left(\mathrm{J} \mathrm{kg}^{-1}\right)$ area averaged over the box indicated in Figure 5. 
c)

Convective Precipitation

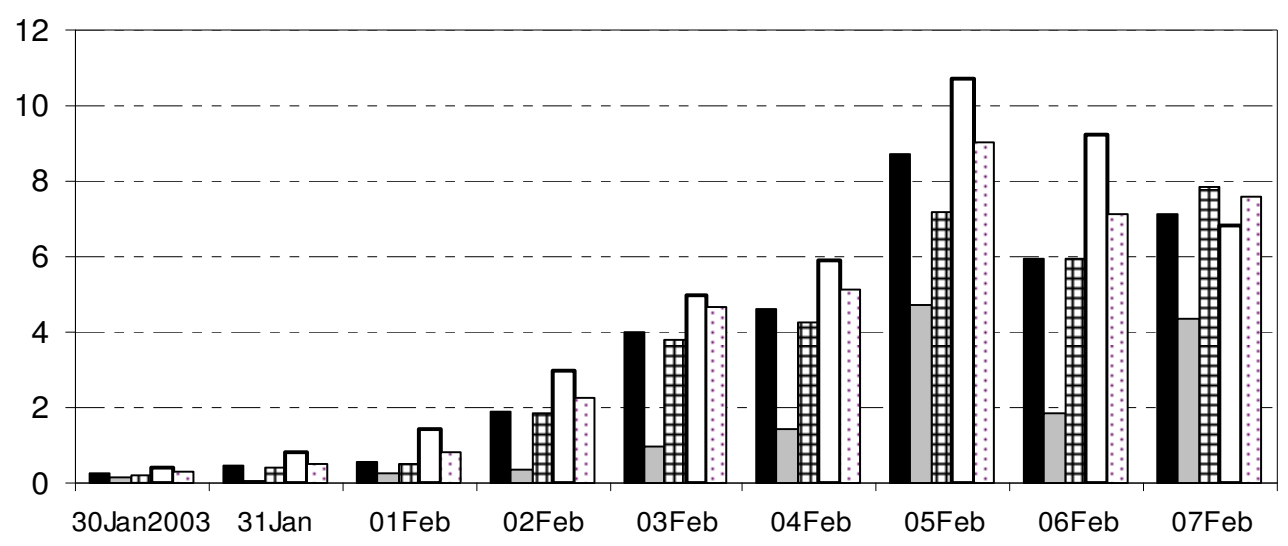

d)

Large Scale Precipitation
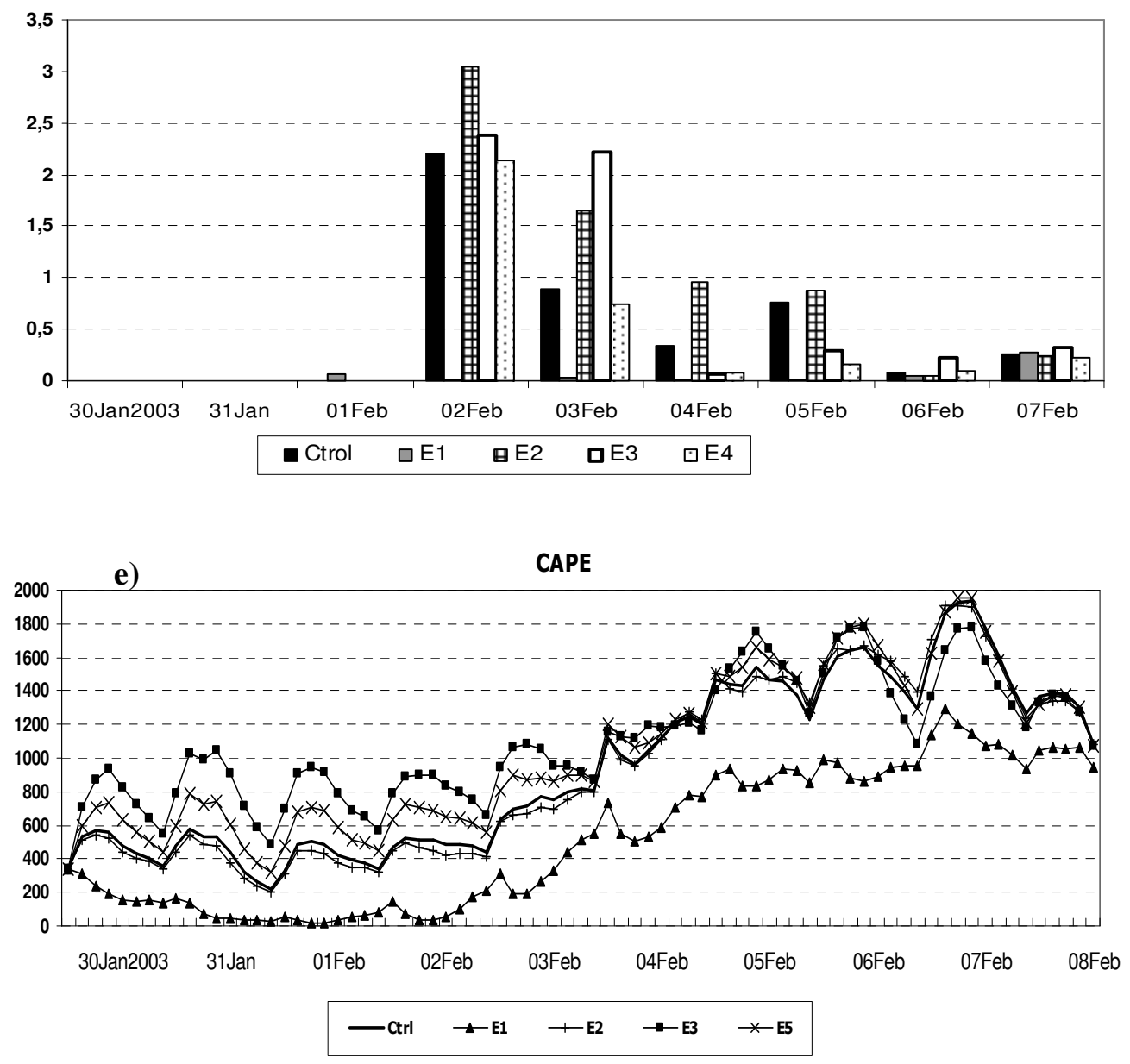

Figure 6: continued 


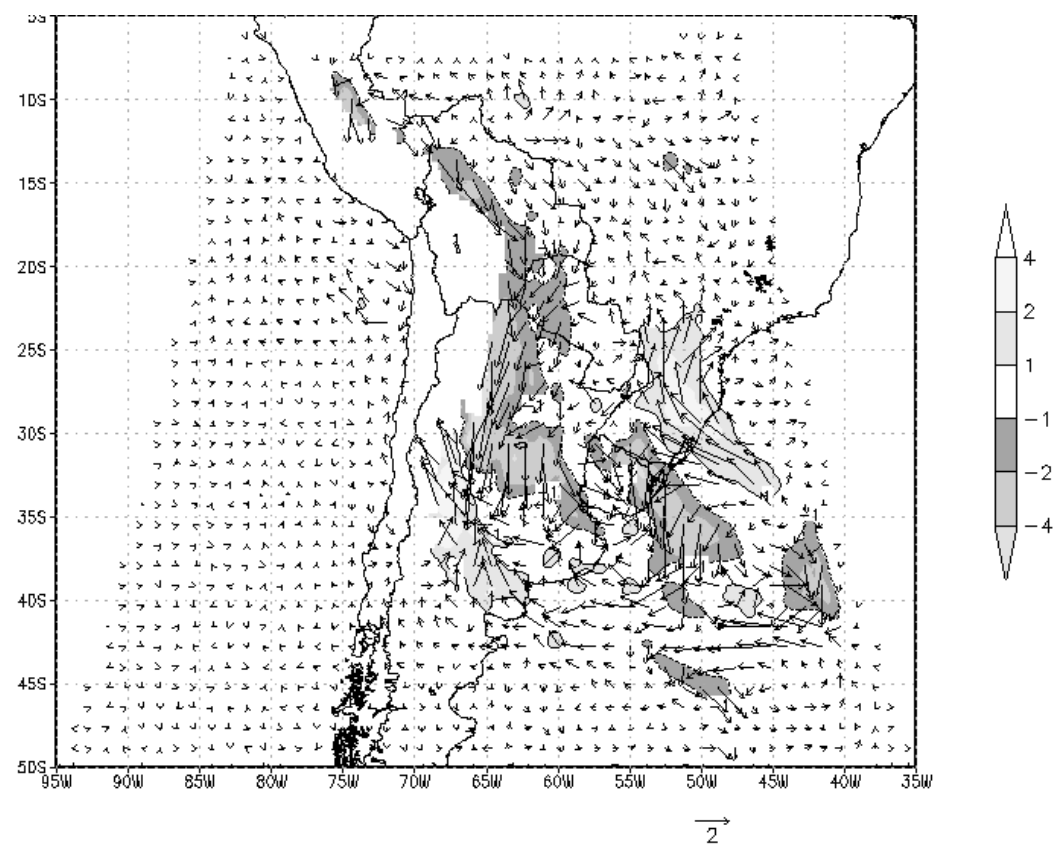

(a)

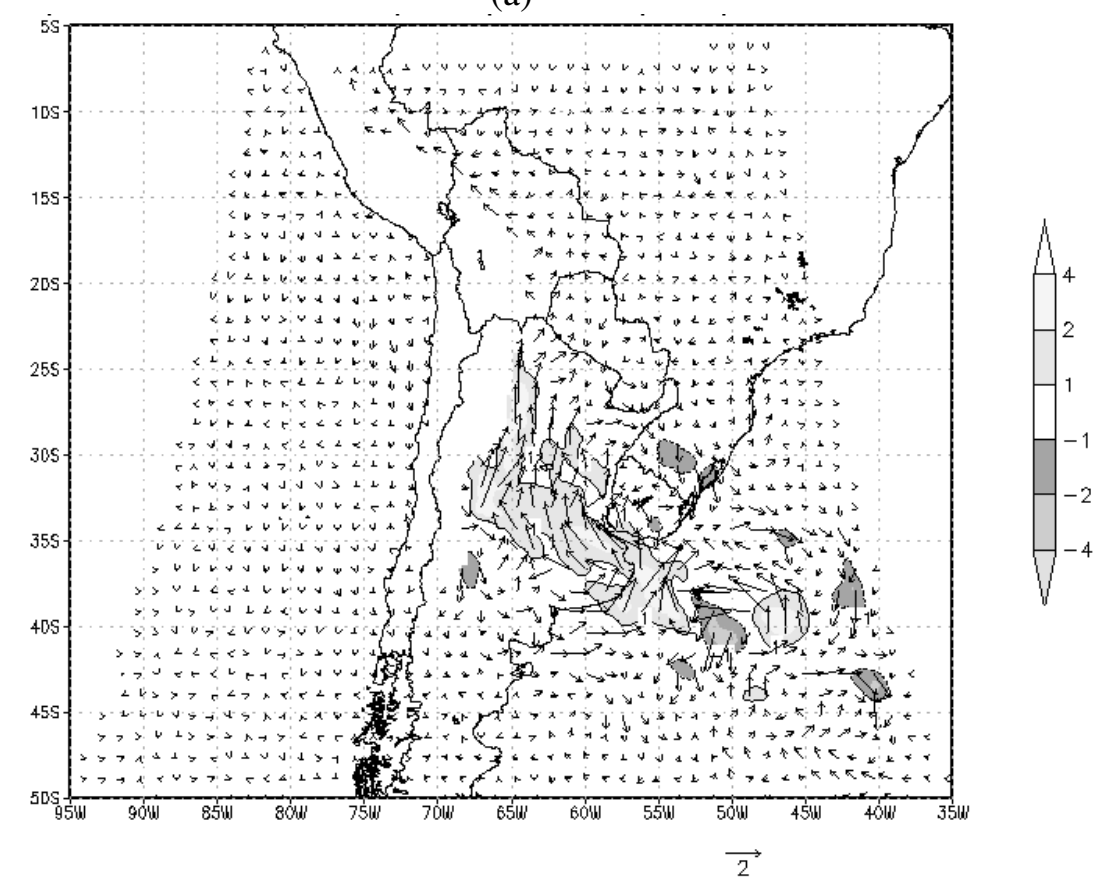

(b)

Figure 7: Mean wind anomalies in $\mathrm{m} \mathrm{s}^{-1}$ at 0900 UTC for a) E1-CTRL and b) E3CTRL 


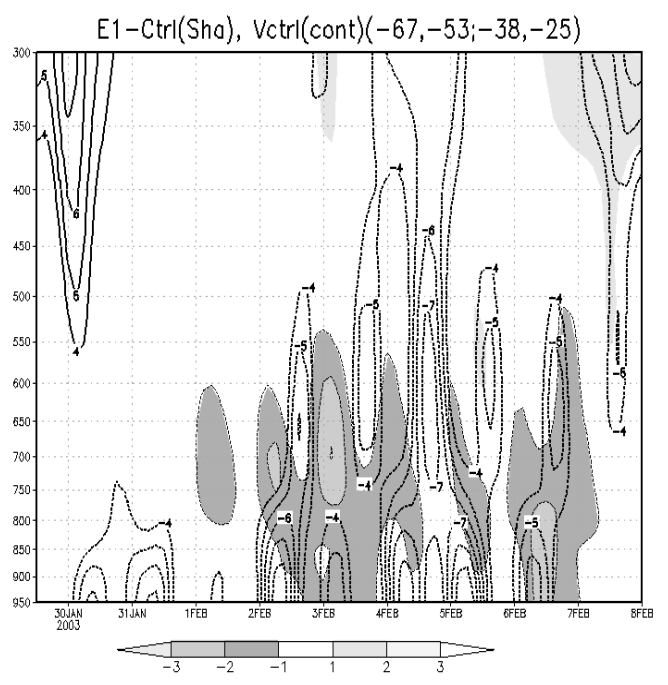

Figure 8: Mean meridional wind speed $\left(\mathrm{ms}^{-1}\right)$ vertical cross section for the CTRL run (contours) and its anomaly (E1-CTRL, shaded), averaged in the box indicated in Figure 5. 


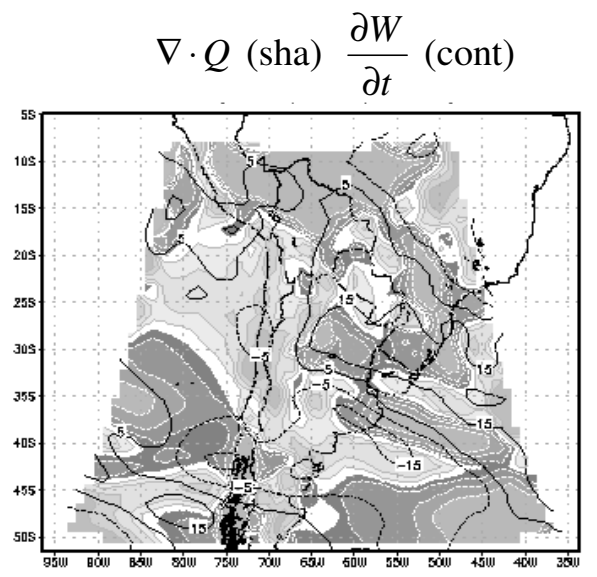

(a)

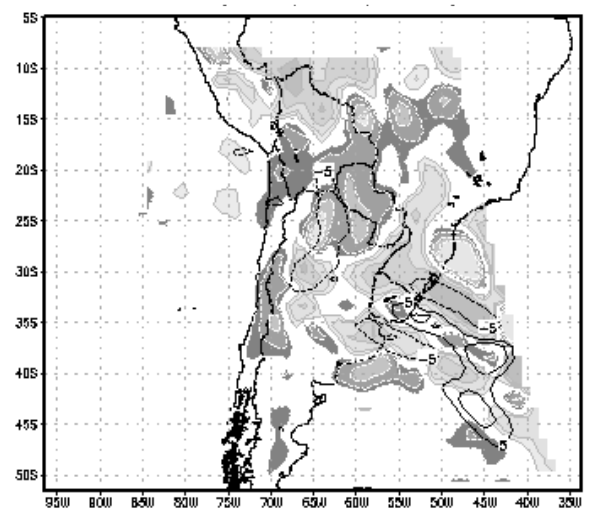

(c)
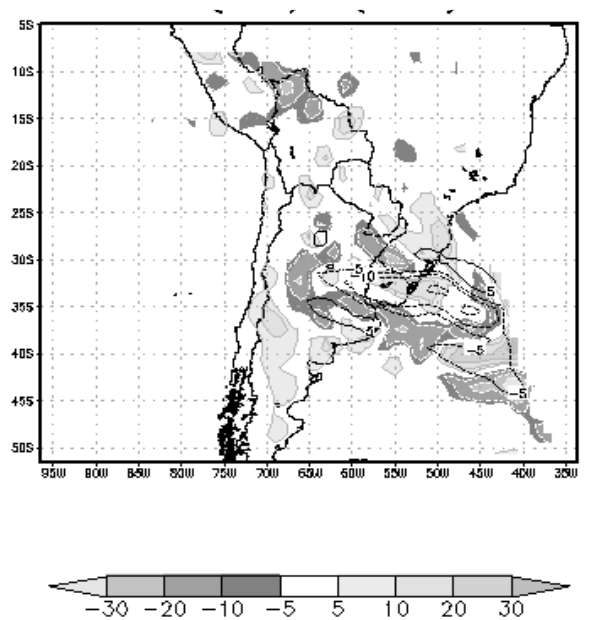

(e)
$\mathrm{P}$ (sha) $\mathrm{E}$ (cont)

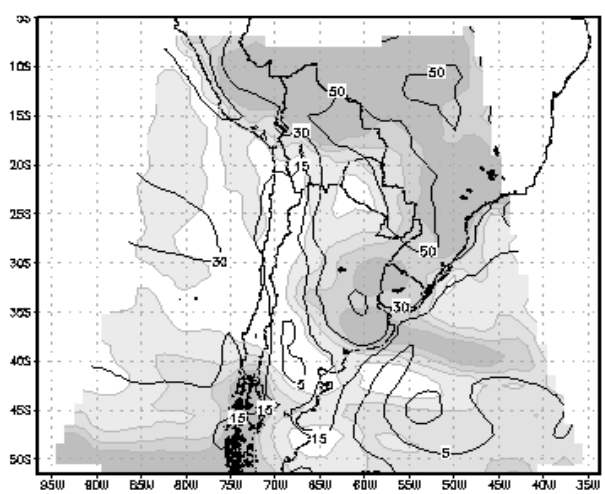

(b)

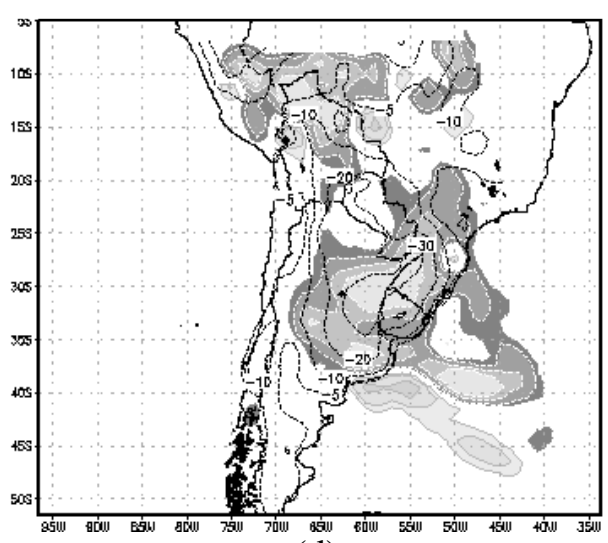

(d)
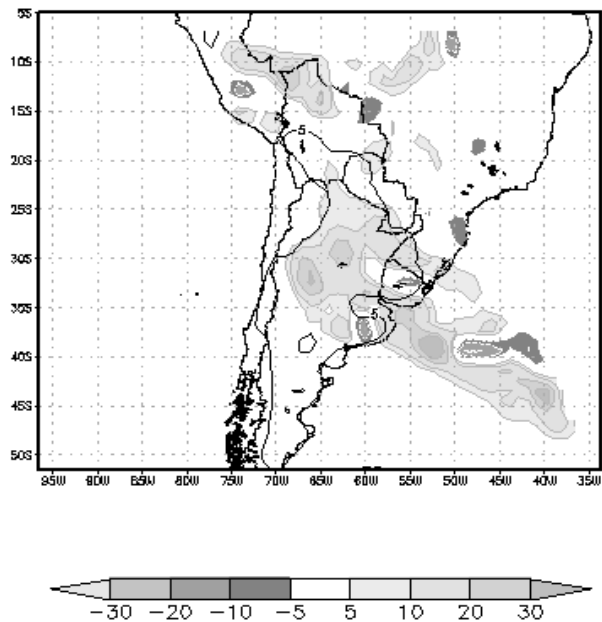

(f)

Figure 9: Temporally integrated water vapor balance equation terms $(\mathrm{mm})$ for the whole run. CTRL run ( $a$ and $b$ ) and differences E1-CTRL (c and d) and E3-CTRL (e and f). Left columns: moisture flux divergence (shaded) and moisture storage change (contours). Right columns: precipitation (shaded) and evaporation (contours). 
INPE ePrint: sid.inpe.br/mtc-m18@80/2009/09.18.13.51 v1 2009-09-19 